\title{
Stable heterologous expression of biologically active terpenoids in green plant cells
}

\author{
N. Kusaira B. K. Ikram ${ }^{1,2}$, Xin Zhan ${ }^{1}$, Xi-Wu Pan ${ }^{1}$, Brian C. King ${ }^{1}$ and Henrik T. Simonsen ${ }^{1 *}$ \\ 1 Department of Plant and Environmental Sciences, Copenhagen Plant Science Centre, University of Copenhagen, \\ Copenhagen, Denmark, ${ }^{2}$ Institute of Biological Sciences, Faculty of Science, University of Malaya, Kuala Lumpur, Malaysia
}

\section{OPEN ACCESS}

Edited by:

Kim Henrik Hebelstrup,

University of Aarhus, Denmark

Reviewed by:

Angharad Margaret Roscoe

Gatehouse,

Newcastle University, UK

Wusirika Ramakrishna,

Michigan Technological

University, USA

*Correspondence:

Henrik T. Simonsen,

Plant Biochemistry Laboratory,

Department of Plant and

Environmental Sciences,

University of Copenhagen,

Thorvaldsensvej 40,

1871 Frederiksberg, Denmark

hts@plen.ku.dk

Specialty section:

This article was submitted to Plant Biotechnology, a section of the journal

Frontiers in Plant Science

Received: 28 November 2014

Accepted: 18 February 2015

Published: 18 March 2015

Citation:

Ikram NKBK, Zhan X, Pan X-W, King $B C$ and Simonsen HT (2015) Stable heterologous expression of biologically active terpenoids in green

plant cells. Front. Plant Sci. 6:129. doi: 10.3389/fpls.2015.00129
Plants biosynthesize a great diversity of biologically active small molecules of interest for fragrances, flavors, and pharmaceuticals. Among specialized metabolites, terpenoids represent the greatest molecular diversity. Many terpenoids are very complex, and total chemical synthesis often requires many steps and difficult chemical reactions, resulting in a low final yield or incorrect stereochemistry. Several drug candidates with terpene skeletons are difficult to obtain by chemical synthesis due to their large number of chiral centers. Thus, biological production remains the preferred method for industrial production for many of these compounds. However, because these chemicals are often found in low abundance in the native plant, or are produced in plants which are difficult to cultivate, there is great interest in engineering increased production or expression of the biosynthetic pathways in heterologous hosts. Although there are many examples of successful engineering of microbes such as yeast or bacteria to produce these compounds, this often requires extensive changes to the host organism's metabolism. Optimization of plant gene expression, post-translational protein modifications, subcellular localization, and other factors often present challenges. To address the future demand for natural products used as drugs, new platforms are being established that are better suited for heterologous production of plant metabolites. Specifically, direct metabolic engineering of plants can provide effective heterologous expression for production of valuable plant-derived natural products. In this review, our primary focus is on small terpenoids and we discuss the benefits of plant expression platforms and provide several successful examples of stable production of small terpenoids in plants.

Keywords: terpenoid production, Physcomitrella patens, Nicotiana tabacum, plants, Artemisia annua

\section{Introduction}

Plants are capable of biologically synthesizing a wide array of specialized metabolites. This is reflected in the total number of specialized metabolites reported as well as the structural complexity of individual compounds. These small organic molecules often mediate biological interactions, and may possess bioactive properties that are useful for humans. This makes many specialized plant compounds of high commercial interest to the biotech industry (Cragg et al., 2011). Many of these commercially interesting compounds are terpenoids, and are widely used as flavors, fragrances, pharmaceuticals, nutraceuticals, 
and industrial chemicals (Berger, 2007; Zwenger and Basu, 2008). Examples of currently marketed drugs originating from a biologically produced terpenoid include artemisinin (sesquiterpenoid), taxol (diterpenoid), and vincristine (meroterpenoid). All of these compounds are highly complex molecules that are commercially obtained from plant starting material. More than 45,000 terpenoids have been identified and this number is increasing (Hamberger and Bak, 2013). They are derived by sequential additions of five carbon isoprene units known as isopentenyl pyrophosphate (IPP). Depending on the number of isoprene units, terpenoids are classified as mono- ( 2 units), sesqui- (3 units), di-(4 units), tri- (6 units), and so forth. These diphosphate molecules allow for a vast diversity in the core structures when cyclized, forming a backbone upon which secondary modifications often occur, further increasing the diversity. The individual biosynthesis of such unique molecules is often highly complex and involves several classes of enzyme such as terpene synthases, cytochromes P450, and acyl transferases (Drew et al., 2009; Góngora-Castillo et al., 2012; Asada et al., 2013; Drew et al., 2013; Hamberger and Bak, 2013; Weitzel and Simonsen, 2013; Pateraki et al., 2015).

For many bioactive terpenoids of interest to the pharmaceutical, food, or fragrance industries, heterologous expression in engineered organisms is the most commercially sustainable method of production, due to the limited availability from natural sources or the structural complexity of the target compound (Simonsen et al., 2009; Daviet and Schalk, 2010; Nielsen et al., 2014). This however requires extensive knowledge about the native in planta biosynthesis of terpenoids in what are often complex metabolic networks, as opposed to linear biosynthetic pathways leading to a single product. Elucidating the biosynthetic route to a target metabolite can take several years of study on just one compound and its biosynthesis (Pickel et al., 2012; Weitzel and Simonsen, 2013; Pateraki et al., 2014, 2015).

In the past 20 years, there have been numerous examples of engineering plants for boosting and altering endogenous isoprenoid metabolism as well as heterologous expression of terpenoid biosynthetic pathways from other species, aiming to improve traits for better disease resistance, weed and pest control, and enhanced ornamental or nutrition properties. See (Table 1) for an overview of the plants and experiments discussed here.

\section{Overall Terpenoid Biosynthesis and Molecular Regulation}

Optimization of general isoprenoid metabolism is a wellestablished strategy to enhance the productivity of terpenoid specialized metabolism. The goal is to increase the amount of carbon going into dedicated isoprenoid precursors, pushing metabolic flux through to the final biologically active specialized metabolite. The engineering strategy often involves over-expression of the 2-C-methyl-D-erythritol-4-phosphate (MEP) and mevalonic acid (MVA) pathway rate-limiting genes. For the MEP pathway, these enzymes include 1-deoxy-D-xylulose-5-phosphate synthase (DXS), 1-Deoxy-D-xylulose 5-phosphate reductoisomerase (DXR), and (E)-4-hydroxy-3-methylbut-2-enyl diphosphate reductase (HDR). For the MVA pathway, the rate limiting step is generally considered to be 3-hydroxy-3-methyl-glutaryl-CoA reductase (HMGR) (Enfissi et al., 2005; Carretero-Paulet et al., 2006; Munoz-Bertomeu et al., 2006; Ohto et al., 2009; Song et al., 2012; Paddon et al., 2013). Overexpression of this step has been shown both in microorganisms and in plants to increase terpenoid production (Wang et al., 2012; Paddon et al., 2013). Other approaches target enrichment of the direct isoprenoid precursor pool through up-regulation of the prenyltransferases geranyl diphosphate synthase (GPS), farnesyl diphosphate synthase (FPS), or geranylgeranyl diphosphate synthase (GGPPS) (Takahashi et al., 2007; Bruckner and Tissier, 2013). Additional strategies include knockdown of biosynthetic pathways that compete for precursor molecules, such as knockdown of squalene synthase or gibberellic acid synthesis (Shuiqin et al., 2006; Engels et al., 2008; Wu and Chappell, 2008). However, knockdown can also have unintended negative effects on pathway regulation resulting in altered plant growth (e.g., in rice) and final yield of the desired product (Manavalan et al., 2012; Zhan et al., 2014). Finally engineering transcription factors or promoters controlling key biosynthetic genes is an emerging field, increasing knowledge of promoter design, DNA motifs important for transcription factor binding to promoters, and which transcription factors are active. For artemisinin biosynthesis in the plant Artemisia annua it was found that high and low producing varieties mainly differ in the promoter region of the key gene DBR2 (Yang et al., 2015). This step controls production of either artemisinin or arteannuien B in the plants, and the two promoters have different binding sites for different transcription factors illustrating the importance of this regulation. The choice of promoters for biotechnological production is well-described and numerous promoters are characterized for not only microbial biotechnology, but also for plant biotechnology (Venter, 2007), and modifications of these have become a key approach in metabolite engineering, including the use of synthetic promoters (Blount et al., 2012).

Looking at general isoprenoid metabolism in more detail, terpenoid biosynthesis starts from the universal building block IPP (Figure 1). Two compartmentalized pathways, the cytosolic MVA pathway and the plastidic MEP pathway, are responsible for IPP biogenesis (Rohmer et al., 1993). In contrast to Saccharomyces cerevisiae and Escherichia coli, plants (including the primitive non-vascular land plant Physcomitrella patens) have both pathways for terpenoid biosynthesis. In the MVA pathway, the NADPH-dependent HMGR is considered as the rate-limiting enzyme that has a global control upon the metabolic flux (Stermer et al., 1994; Chappell et al., 1995; Nieto et al., 2009). In the MEP pathway, the first step is the biosynthesis of 1-deoxyD-xylulose-5-phosphate (DXP) by DXS. This is a rate limiting step together with the second step, where DXP is reduced by DXR using NADPH as a cofactor to 2-C-methyl-D-erythritol 4phosphate (Figure 1). In the MEP pathway, HDR has been shown to play a major role in controlling plastid terpenoid biosynthesis along with DXS and DXR (Rodriguez-Concepcion et al., 2004).

In the beginning of both pathways, the isomerization of IPP to DMAPP is catalyzed by isopentenyl pyrophosphate isomerase (IDI), which plays a crucial role in plants. When IDI was 
TABLE 1 | Reports of metabolic engineering of plant terpenoids biosynthesis discussed.

\begin{tabular}{|c|c|c|c|c|}
\hline Overexpressed enzyme(s) & Engineered species & Gene source(s) & Change in terpenoid profile & References \\
\hline 1-deoxy-D-xylulose-5-phosphate synthase (DXS) & Elaeis guineensis & $\begin{array}{l}\text { Elaeis } \\
\text { guineensis-fruits }\end{array}$ & $\beta$-carotene $\uparrow$ & $\begin{array}{l}\text { Khemvong and } \\
\text { Suvachittanont, } 2005\end{array}$ \\
\hline 1-deoxy-D-xylulose-5-phosphate synthase (DXS) & Gingko biloba & Gingko biloba & Ginkgolide $\uparrow$ & Gong et al., 2006 \\
\hline 1-deoxy-D-xylulose-5-phosphate synthase (DXS) & Lavandula latifolia & $\begin{array}{l}\text { Arabidopsis } \\
\text { thaliana }\end{array}$ & Total essential oil $\uparrow$ & $\begin{array}{l}\text { Munoz-Bertomeu et al., } \\
2006\end{array}$ \\
\hline $\begin{array}{l}\text { 1-deoxy-D-xylulose-5-phosphate synthase (DXS), } \\
\text { Deoxyxylulose phosphate reductoisomerase (DXR) }\end{array}$ & Salvia sclarea & $\begin{array}{l}\text { Arabidopsis } \\
\text { thaliana }\end{array}$ & Aethiopinone $\uparrow$ & Vaccaro et al., 2014 \\
\hline $\begin{array}{l}\text { 1-deoxy-D-xylulose-5-phosphate synthase (DXS), } \\
\text { Geranylgeranyl diphosphate synthase (GGPPS) } \\
\text { 3-hydroxy-3-methylglutaryl-CoA reductase (HMGR) }\end{array}$ & Salvia miltiorrhiza & Salvia miltiorrhiza & Tanshinone $\uparrow$ & Kai et al., 2011 \\
\hline $\begin{array}{l}\text { Amorpha-4,11-diene synthase (ADS) } \\
\text { Amorpha-4,11-diene oxidase (CYP71AV1) } \\
\text { Artemisinic aldehyde } \Delta 11(13) \\
\text { Double-bond reductase (DBR2) }\end{array}$ & Nicotiana tabacum & Artemisinia annua & $\begin{array}{l}\text { Amorpha-4,11-diene } \uparrow, \\
\text { artemisinic alcohol } \uparrow, \\
\text { dihydroartemisinic alcohol } \uparrow\end{array}$ & $\begin{array}{l}\text { Wallaart et al., } 2001 \\
\text { Zhang et al., } 2011\end{array}$ \\
\hline $\begin{array}{l}\text { Amorpha-4,11-diene synthase (ADS) } \\
\text { 3-hydroxy-3-methylglutaryl-CoA reductase (HMGR) } \\
\text { Farnesyl diphosphate synthase (FPS) } \\
\text { Amorpha-4,11-diene oxidase (CYP71AV1) }\end{array}$ & Nicotiana benthamiana & Artemisinia annua & $\begin{array}{l}\text { Amorpha-4,11-diene } \uparrow \\
\text { Artemisinic acid-12- } \beta \text {-diglucoside } \\
\uparrow\end{array}$ & Van Herpen et al., 2010 \\
\hline Deoxyxylulose phosphate reductoisomerase (DXR) & Mentha $\times$ piperita & Mentha $\times$ piperita & Total essential oil $\uparrow$ & $\begin{array}{l}\text { Mahmoud and } \\
\text { Croteau, } 2001\end{array}$ \\
\hline $\begin{array}{l}\text { Deoxyxylulose phosphate reductoisomerase (DXR), } \\
\text { Amorpha-4,11-diene oxidase (CYP71AV1), } \\
\text { Cytochrome P450 reductase (CPR) }\end{array}$ & Artemisinia annua & Artemisinia annua & Artemisinin $\uparrow$ & Xiang et al., 2012 \\
\hline Farnesyl diphosphate synthase (FPS) & Artemisinia annua & Artemisinia annua & Artemisinin $\uparrow$ & Han et al., 2006 \\
\hline Geraniol synthase (GES) & Nicotiana tabacum & Valeriana officinalis & Geraniol $\uparrow$ & Vasilev et al., 2014 \\
\hline Limonene synthase (LS) & Nicotiana tabacum & Perilla frutescens & Limonene $\uparrow$ & Ohara et al., 2003 \\
\hline $\begin{array}{l}\text { Limonene-3-hydroxylase (LIM3H), } \\
\gamma \text {-terpinene cyclase (TER) } \\
\text { (+)-limonene cyclase1 (LIM) } \\
\text { (-)- } \beta \text {-pinene cyclase (PIN) }\end{array}$ & $\begin{array}{l}\text { Nicotiana tabacum } \\
\text { (Petit Havana, SR1) }\end{array}$ & Mentha picata & $\begin{array}{l}\text { (+)-trans-isopiperitenol } \uparrow, \\
1,3,8-p \text {-menthatriene } \uparrow, \\
1,5,8-p \text {-menthatriene } \uparrow, \\
p \text {-cymene } \uparrow, \text { isopiperitenone } \uparrow\end{array}$ & Lücker et al., 2004a \\
\hline Nerolidol Synthase 1 (FaNES1) & Arabidopsis thaliana & Fragaria ananassa & $\begin{array}{l}\text { Linalool } \uparrow, \text { nerolidol } \uparrow \\
\text { E-8-OH-6,7-dihydrolinalool } \uparrow \\
\text { E-8-OH-linalool } \uparrow\end{array}$ & Aharoni et al., 2003 \\
\hline $\begin{array}{l}\text { Patchoulol synthase (PTS) } \\
\text { Farnesyl diphosphate synthase (FPS) }\end{array}$ & Nicotiana tabacum & Pogostemon cablin & Patchoulol $\uparrow$ & Shuiqin et al., 2006 \\
\hline $\begin{array}{l}\text { Patchoulol synthase (PTS) } \\
\text { Truncated } \\
\text { 3-hydroxy-3-methylglutaryl-CoA-reductase } \\
\text { (tHMGR) }\end{array}$ & Physcomitrella patens & $\begin{array}{l}\text { Pogostemon cablin } \\
\text { Physcomitrella } \\
\text { Patens (tHMGR) }\end{array}$ & $\begin{array}{l}\text { Patchoulol } \uparrow, \\
\text { Ent-16- } \alpha-\mathrm{OH} \text {-kaurene } \downarrow\end{array}$ & Zhan et al., 2014 \\
\hline Sclareol synthase 1 and 2 (SsLPPS and SsSS) & Physcomitrella patens & Salvia sclarea & Sclareol $\uparrow$ & Pan, 2014 \\
\hline S-linalool synthase (LIS) & $\begin{array}{l}\text { Dianthus caryophyllus } \\
\text { (Carnation) }\end{array}$ & Clarkia breweri & $\begin{array}{l}\text { Linalool } \uparrow \text {, cis- and trans-linalool } \\
\text { oxide } \uparrow\end{array}$ & Lavy et al., 2002 \\
\hline S-linalool synthase (LIS) & $\begin{array}{l}\text { Lycopersicon } \\
\text { esculentum (Tomato) }\end{array}$ & Clarkia breweri & $\begin{array}{l}S \text {-linalool } \uparrow, 8-\mathrm{OH} \text {-linalool } \uparrow \text {, other } \\
\text { volatiles } \uparrow\end{array}$ & Lewinsohn et al., 2001 \\
\hline S-linalool synthase (LIS) & Petunia hybrida W115 & Clarkia breweri & S-linalyl- $\beta$-glucopyranoside $\uparrow$ & Lücker et al., 2001 \\
\hline Taxadiene synthase (TXS) & Arabidopsis thaliana & Taxus baccata & Taxadiene $\uparrow$ & Besumbes et al., 2004 \\
\hline Taxadiene synthase (TXS) & $\begin{array}{l}\text { Lycopersicon } \\
\text { esculentum Ailsa Craig } \\
\text { (Yellow tomato) }\end{array}$ & Taxus baccata & Taxadiene $\uparrow$ & Kovacs et al., 2007 \\
\hline Taxadiene synthase (TXS) & Physcomitrella patens & Taxus brevifolia & Taxadiene $\uparrow$ & Anterola et al., 2009 \\
\hline$\alpha / \beta$-santalene (STS) & Physcomitrella patens & Santalum album & $\alpha / \beta$-santalene $\uparrow$ & Zhan et al., 2014 \\
\hline $\begin{array}{l}\gamma \text {-terpinene cyclase (TER) } \\
(+) \text {-limonene cyclase1 (LIM) } \\
(-)-\beta \text {-pinene cyclase (PIN) }\end{array}$ & $\begin{array}{l}\text { Nicotiana tabacum } \\
\text { (Petit Havana, SR1) }\end{array}$ & Citrus $x$ limon & $\begin{array}{l}\beta \text {-pinene } \uparrow \text {, limonene } \uparrow, \\
\gamma \text {-terpinene } \uparrow\end{array}$ & Lücker et al., 2004b \\
\hline
\end{tabular}

All the reports have used a strategy based on over expression of the described gene(s) in their experiments. The table was adapted and updated from Lange and Ahkami (2013). 


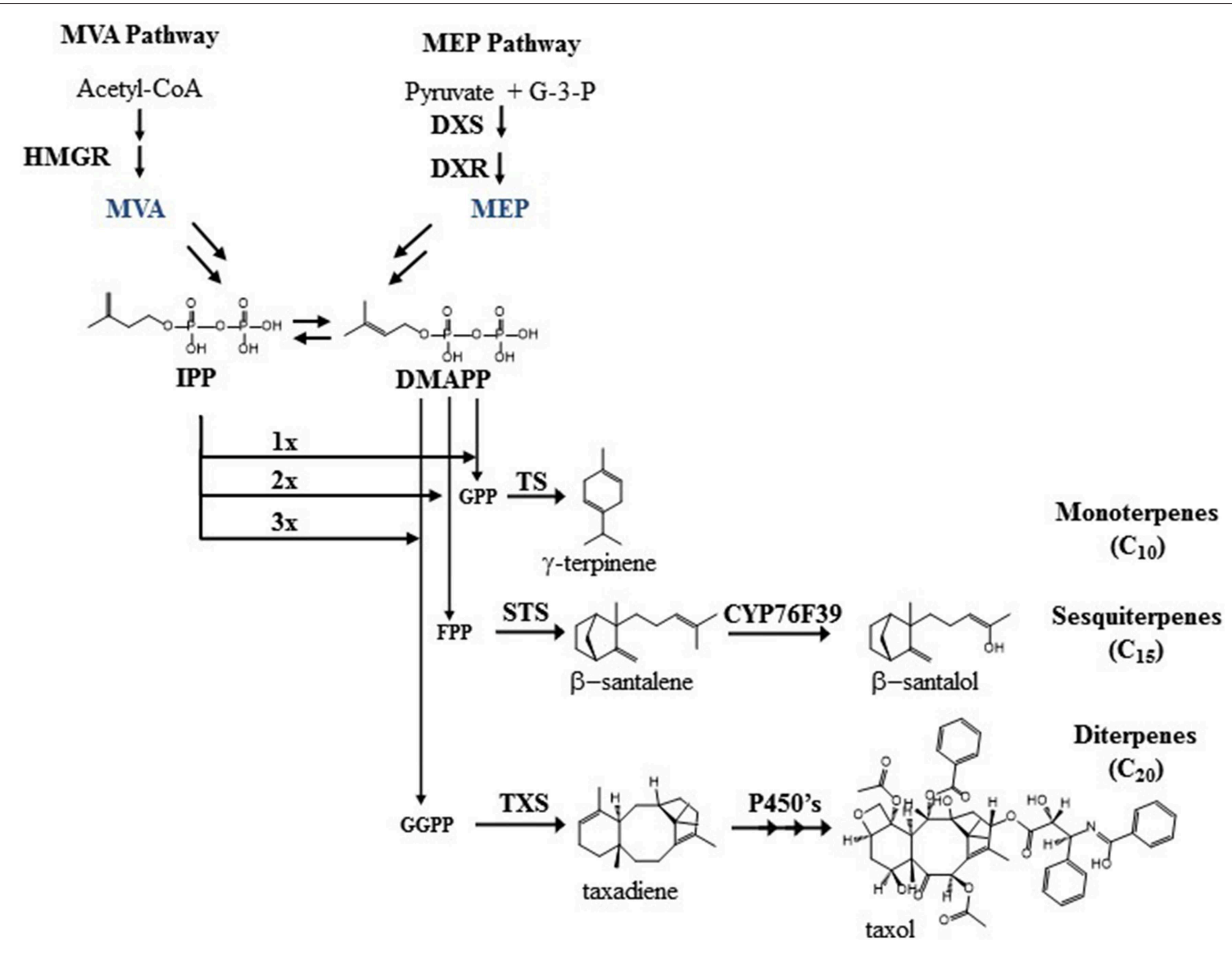

FIGURE 1 | The figure show the overall MVA and MEP pathway, along with examples of mono-, sesqui-, and diterpenoids biosynthesis also described in the text.

disrupted in either Nicotiana benthamiana (Page et al., 2004) or Arabidopsis thaliana (Okada et al., 2008) up to $80 \%$ reduction in chlorophylls, phytosterols, and carotenoids was observed.

As the universal precursors of terpenoid biosynthesis, IPP and DMAPP are polymerized by prenyltransferases such as GPS, FPS, and GGPPS, followed by terpene synthases (TPS) that utilize GPP, FPP, or GGPP as substrates. GPS and GGPPS are mainly found in the plastids and FPS is found in the cytosol. As the precursor pathways and metabolite pools are generally compartmentalized in plants, so follows the specialized metabolism with monoterpene synthases and diterpene synthases working in the plastid whilst sesquiterpene synthases are usually found in the cytosol. However, some cases of ambiguous sub-cellular location of these enzymes contribute to a more complex pattern of terpenoid biosynthesis. For example, in Lithospermum erythrorhizon, GPS is found in the cytosol instead of the chloroplast, and in rice and wild tomato, FPS is found in both the chloroplast and the cytosol. The chloroplastic enzyme in wild tomato produces $Z, Z$-FPP instead of E,E-FPP that is the product of the cytosolic enzyme (Sommer et al., 1995; Sanmiya et al., 1999; Sallaud et al., 2009). Likewise, some terpene synthases are found in unexpected subcellular locations, which can further enhance chemical diversity. Examples are the dual plastid/mitochondrial localized
FaNES2 from strawberry, the monoterpene synthase $\alpha$-terpineol synthase from Magnolia, and the monoterpene synthase FvPIN from strawberry that are localized to the cytosol (Aharoni et al., 2004; Lee and Chappell, 2008). The sesquiterpene synthase for santalene and bergamotene from wild tomato is localized to the plastids (Sallaud et al., 2009). In contrast, the essential oil producing plant sandalwood has santalene and santalol biosynthesis localized in the cytosol of cells in the heartwood where a santalene synthase (STS) cyclizes FPP followed by a hydroxylation by CYP76F39 yielding santalol and bergamotene (Diaz-Chavez et al., 2013). The product profile is slightly different between the STS from tomato and sandalwood, and so is the stereochemistry of the compounds. Collectively, the different locations give a more dynamic picture of terpenoid biosynthesis than the classical descriptions, and offer additional biochemical routes to enhance the chemical diversity in future bioengineering projects.

\section{Production of Heterologous Terpenoids in Plants}

There are many examples of successful heterologous expression of terpene biosynthetic genes and increased production levels 
of terpenoids, particularly via microbial hosts. However, most complex plant-derived terpenoids such as taxol and artemisinin require plant cytochrome $\mathrm{P} 450$ enzymes, which are often difficult to express in microbial cells due partially to membrane associations and subcellular targeting, as well as post-translational modifications and insolubility. Thus, complex engineering strategies for expression in microbial hosts are required in order to obtain the complete biosynthesis of the target molecule. Attempts at using plant cells, as heterologous hosts involving cytochromes $\mathrm{P} 450$ are less widespread, mainly because plant transformation techniques are more complex, are not available for many species, require much more time to recover transgenic organisms, and plant growth rates are typically slower than in microbial systems. However, in part due to their native cytochrome $\mathrm{P} 450$-related biosynthetic pathways, plant cells may be more desirable to engineer plant pathways compared to the microbial options. Several expression studies using plant cells for heterologous terpenoid production have been carried out, and we will focus mainly on examples in Nicotiana spp., A. thaliana, and $P$. patens (see Table $\mathbf{1}$ ).

Expression of amorphadiene synthase from Artemisia annua in N. tabacum resulted in the production of amorphadiene, yielding 0.2-1.7 ng/g (Wallaart et al., 2001). Adding two additional artemisinin biosynthetic genes yielded $4 \mathrm{mg} / \mathrm{g}$ fresh weight of amorphadiene in leaves and $0.01 \mathrm{mg} / \mathrm{g}$ dry weight of artemisinic alcohol (Zhang et al., 2011). Following the successful amorphadiene production in $N$. tabacum, $N$. benthamiana was then considered as another production platform for artemisinin precursors. The study aimed to produce artemisinic acid by combined transient expression of amorphadiene synthase targeted to the mitochondria, followed by mitochondrial FPS and cytosolic HMGR co-expressed using a ribosomal-skip construct. These genes were co-infiltrated with CYP71AV1 (amorphadiene oxidase) and the plants produced artemisinic acid-12- $\beta$-diglucoside at $39.5 \mathrm{mg} / \mathrm{kg}$ fresh weight instead of artemisinic acid. It has been suggested that the expressed artemisinic acid was further modified by a native glycosyl transferase into artemisinic acid-12- $\beta$-diglucoside (Van Herpen et al., 2010; Ting et al., 2013).

Another example explored stable heterologous expression in Nicotiana of the monoterpenoid geraniol synthase from Valeriana officinalis (VoGES) and compared several N. tabacum and $N$. benthamiana systems. This study compared productivity of stable and transient expression and different growth conditions including whole plants and cell cultures. The authors observed highest geraniol yield in stable transgenic plants grown in the greenhouse, and 10-fold reduction when plants were grown in vitro. However, they also conclude that cell suspension cultures were superior to either hairy root cultures or greenhouse plants due to the relatively high biomass yield and short cultivation time (9 days compared to 6-9 weeks) and suggest that cell cultures could be the most economically viable option for large scale production (Vasilev et al., 2014).

Production of patchoulol has also been shown in tobacco at $0.030 \mathrm{mg} / \mathrm{g}$ and volatile emission of $50-100 \mathrm{ng} / \mathrm{h}$ fresh weight in the leaves. It was shown that redirecting the production of sesquiterpenoids from the cytosol to the plastids increased the overall yield by 40,000 fold (Shuiqin et al., 2006).
Another well-researched plant host for gene overexpression is Arabidopsis thaliana. Taxadiene synthase (TXS) from Taxus baccata was expressed in Arabidopsis, which led to production of taxadiene, a key step of paclitaxel/Taxol biosynthesis. Taxadiene accumulation was reported to be about $20 \mathrm{ng} / \mathrm{g}$ dry weight produced in both seedlings and leaves from the transgenic lines (Besumbes et al., 2004). Besides Arabidopsis, TXS has also been expressed in yellow tomato, where redirecting GGPP from making carotenoids into producing taxadiene resulted in $160 \mathrm{mg}$ from $1 \mathrm{~kg}$ of freeze dried fruit (Kovacs et al., 2007).

The moss Physcomitrella patens is an attractive alternative for production of plant biopharmaceuticals due to the fact that it can be scaled up in liquid cultures in large bioreactors and genetically modified using homologous recombination. Mosses have a simple terpenoid profile, which facilitates a clean metabolic background. Despite this simple profile, $P$. patens produces large quantities of endogenous diterpenes (Von Schwartzenberg et al., 2004). A combination of these factors makes moss an attractive host for heterologous terpenoid biosynthesis. For example, the expression of TXS in Physcomitrella patens produces taxadiene without any phenotypic change, making it a promising host for the production of paclitaxel (Anterola et al., 2009). In addition, recently published work demonstrated successful production of two important sesquiterpenoids for the fragrance industry in moss, patchoulol and $\beta$-santalene, with productivity up to 1.3 $\mathrm{mg} / \mathrm{g}$ and $0.039 \mathrm{mg} / \mathrm{g}$ dry weight, respectively (Zhan et al., 2014). In this study, overexpression of a truncated HMGR lacking a regulatory domain either from moss itself or from yeast gave an increase in patchoulol levels. Another important diterpenoid for the fragrance industry, sclareol, was also recently produced in moss, with yield that yielded $2.84 \mathrm{mg} / \mathrm{g}$ dry weight in the highest producing moss line (Pan, 2014).

\section{Transgenic Events Negatively Affected Primary Metabolism}

Metabolic engineering of terpenoid biosynthesis pathways in plants could have physiological and ecological costs, as demonstrated by growth retardation following DXR over-expression in peppermint for the high yield of essential oil (Mahmoud and Croteau, 2001). Similar issues have been observed in Arabidopsis and tomato, where heterologous expression of taxadiene synthase (TXS), linalool/nerolidol synthase (FaNES1), phytoene synthase (PSY), or geraniol synthase (GES) negatively affected the biosynthesis of primary metabolites (Busch et al., 2002; Aharoni et al., 2003; Besumbes et al., 2004; Davidovich-Rikanati et al., 2007). One explanation for these phenotypes might be due to a toxic effect in plant cells. A more detailed study in maize, which explored heterologous biosynthesis of $(E)$ - $\beta$-caryophyllene and $\alpha$-humulene, suggested that the costs such as compromised seed germination, plant growth, and yield outweighed its potential benefits such as repelling root herbivores (Robert et al., 2013). Silencing of (E)-4-hydroxy-3-methylbut-2-enyl diphosphate synthase (HDS) and isopentenyl/dimethylallyl diphosphate synthase (IDS) also negatively affect the level of chlorophyll and carotenoids in leaves compared to controls (Page et al., 2004). Two reasonable possibilities could explain such costs: depletion of precursor for the primary metabolites, and the toxicity of desired products (Fray et al., 1995; Aharoni et al., 2003). 


\section{Production Hosts-Microbial vs. Plant Platforms}

The most popular hosts used for the production of natural products, including terpenoids, are E. coli and S. cerevisiae. These two microorganisms are well-established and there is a large body of knowledge and genetic resources for them, including wholecell computer models (Atlas et al., 2008). Versatile molecular cloning tools and accessibility of scale-up in industry are additional advantages of these microbial platforms. E. coli has been used for production of artemisinin precursors. A modified E. coli strain together with a superior fermentation process was able to accumulate more than $25 \mathrm{~g} / \mathrm{L}$ amorpha-4,11-diene (precursor of artemisinic acid and artemisinin) in the culture (Tsuruta et al., 2009). However, the challenges of expressing plant cytochromes P450 (e.g., CYP71AV1 for artemisinic acid synthesis) makes $E$. coli a less suitable host for complex terpenoid production, due to the need of these enzymes for further product modification and precise membrane associations. In such cases, the baker's yeast S. cerevisiae has been used as a eukaryotic expression host, especially when only one cytochrome P450 is involved. By introducing the genes responsible for artemisinic acid synthesis, including CYP71AV1 and its redox partner POR (cytochrome P450 oxidoreductase), engineered yeast is capable of producing high titers (more than $100 \mathrm{mg} / \mathrm{l}$ ) of artemisinic acid (an intermediate in the artemisinin biosynthesis pathway). This level of expression is significantly higher than in Artemisia annua, the natural producer of artemisinin (Ro et al., 2006). The commercialization of yeastbased pharmaceuticals such as artemisinin (Paddon et al., 2013), the forskolin precursor manoyl oxide (Nielsen et al., 2014; Pateraki et al., 2014), and some fragrance compounds is imminent, or already available.

Metabolic engineering of plant metabolism is far more complicated and time consuming as compared to the established microbial systems. In depth understanding of the metabolic system and regulatory complexity would be very helpful to manipulate the system without disrupting other metabolic processes within the plant. Compared to microbial platforms, plants are generally not regarded as a first-choice platform for terpenoid production due to the more complicated metabolic network, difficulty of stable transformation, longer growth cycles, and challenges in industrial scale-up of cell cultures. However, a major limitation of many microbial expression systems, in particular the use of bacterial systems, is that they are unable to carry out the necessary post-translation modification essential for correct folding and subsequent protein function. As such, many of these microbial systems produce eukaryotic enzymes that are not functionally active. Additionally, as photoautotrophic organisms, plants have their own advantages including the capability of utilizing carbon dioxide as a carbon source, light-driven biosynthesis, and growth in open fields or greenhouses. This means that plants could potentially be grown in more environmentally friendly ways and have a smaller carbon footprint than industrial bioreactors for yeast and bacteria. Monocots (duckweed, maize), dicots (alfalfa, $N$. benthamiana), and bryophytes $(P$. patens) are used to produce therapeutic proteins (Faye and Gomord, 2009; Buttner-Mainik et al., 2011; Bach et al., 2014a,b).
As described previously, $P$. patens can also be used to produce both sesqui- and diterpenoids and is readily scaled-up in illuminated bioreactors (Anterola et al., 2009; Pan, 2014; Zhan et al., 2014). Terpenoid production in algae is also an attractive option but much work needs to be done before an industrial application is available (Lohr et al., 2012). Another advantage of heterologous expression in plant platforms is that increasing endogenous terpenoid products in the native plants may improve the nutritional value (such as carotenoids, pro-vitamin A) of food crops as well as enhancing plant fitness by increasing the resistance to herbivores, pathogens, or pests (Ye et al., 2000; Beale et al., 2006; Munoz-Bertomeu et al., 2006; Beyer, 2010).

\section{Metabolic Regulation for Successful Plant Terpenoid Engineering}

Due to the importance of terpenoids in growth, development, and survival, plants have evolved a complicated network to regulate terpene biosynthesis in different layers (Chappell, 1995; McGarvey and Croteau, 1995). In general, for the MEP pathway up or down-regulation of the rate-limiting DXS and DXR genes will positively or negatively affect the overall biosynthesis of plastidial terpenoids including carotenoids, chlorophylls as well as heterologous terpenes (Estevez et al., 2001; CarreteroPaulet et al., 2006). These two genes are regulated by light, developmental cues and biotic elicitors at transcriptional and post-transcriptional levels (Walter et al., 2000; Okada et al., 2007; Cordoba et al., 2009; Han et al., 2013). For instance, the DXS transcript was at a higher level in the young leaves and inflorescences of tomato as well as the ripening fruit, but not in the root indicating a light inducible regulation (Lois et al., 2000). HMGR, the key regulatory step in the MVA pathway is regulated in response to a variety of developmental and environmental stress factors (Choi et al., 1994; Weissenborn et al., 1995). HMGR is regulated at the transcriptional, translational, and post-translational levels (Stermer et al., 1994; Nieto et al., 2009).

Efforts have been made to enhance the production of terpenoid bioactive compounds by modulating the MEP and MVA activity to boost production. This is shown in the production of essential oil in mint that gives up to $40 \%$ increase of essential oils (Lange and Croteau, 1999) due to an increase in deoxyxylulose phosphate reductoisomerase (DXR) activity by overexpression of the DXR gene. Overexpression of DXS from Arabidopsis in spike lavender also led to an increased yield of essential oils with 3.5 fold in leaves and 6 fold in flowers compared to controls (MunozBertomeu et al., 2006). A similar situation can be observed on the production of ginkgolide in Ginkgo biloba (Gong et al., 2006), $\beta$-carotene in Elaeis guineensis (Khemvong and Suvachittanont, 2005), and carotenoid in A. thaliana (Estevez et al., 2001).

Combining strategies of boosting general isoprenoid metabolism as well as overexpression of genes for specialized metabolism has also given good results. Transgenic Artemisia апnиa expressing three functional artemisinin-related genes, DXR, CYP71AV1, and POR showed higher production levels of artemisinin than the wild type (Xiang et al., 2012). Production was also increased by overexpression of FPS with up to threefold 
increase of artemisinin (Han et al., 2006). Co-expression of FPS and amorpha-4,11-diene synthase (ADS) in the plastids in tobacco likewise increases accumulation of the artemisinin precursor amorpha-4,11-diene (Shuiqin et al., 2006).

In Salvia sclarea hairy root cultures, Vaccaro et al. demonstrated a successful independent overexpression of DXS and DXR from Arabidopsis. The expressed genes enhanced the biosynthesis of diterpenes resulting in a 2.5 fold increase of aethiopinone for DXS and 4.6 fold for DXR (Vaccaro et al., 2014). Previous work by Kai et al. showed that overexpressing DXS, GGPPS, and HMGR in Salvia miltiorrhiza hairy root led to accumulation of tanshinone at about 4.7 fold higher than the control (Kai et al., 2011).

\section{Perspectives}

Engineering of terpenoid biosynthesis in plants introduces several additional challenges compared to microbial hosts. However, plant metabolic engineering also provides additional benefits and opportunities. Knowledge of plant metabolic networks and metabolic trafficking, at both the biochemical and cellular level, has increased. This, along with the fast development of next generation sequencing and novel genetic modification techniques, provide tremendous tools for plant engineering in scales that just a few years ago would have been a daunting task. For example, advances in plant molecular and synthetic biology

\section{References}

Aharoni, A., Giri, A. P., Deuerlein, S., Griepink, F., De Kogel, W. J., Verstappen, F. W., et al. (2003). Terpenoid metabolism in wild-type and transgenic Arabidopsis plants. Plant Cell 15, 2866-2884. doi: 10.1105/tpc.016253

Aharoni, A., Giri, A. P., Verstappen, F. W., Bertea, C. M., Sevenier, R., Sun, Z., et al. (2004). Gain and loss of fruit flavor compounds produced by wild and cultivated strawberry species. Plant Cell 16, 3110-3131. doi: 10.1105/tpc.104.0 23895

Anterola, A., Shanle, E., Perroud, P.-F., and Quatrano, R. (2009). Production of taxa-4(5),11(12)-diene by transgenic Physcomitrella patens. Transgenic Res. 18, 655-660. doi: 10.1007/s11248-009-9252-5

Asada, K., Salim, V., Masada-Atsumi, S., Edmunds, E., Nagatoshi, M., Terasaka, K., et al. (2013). A 7-deoxyloganetic acid glucosyltransferase contributes a key step in secologanin biosynthesis in Madagascar periwinkle. Plant Cell 25, 4123-4134. doi: 10.1105/tpc.113.115154

Atlas, J. C., Nikolaev, E. V., Browning, S. T., and Shuler, M. L. (2008). Incorporating genome-wide DNA sequence information into a dynamic whole-cell model of Escherichia coli: application to DNA replication. IET Syst. Biol. 2, 369-382. doi: 10.1049/iet-syb:20070079

Bach, S. S., Bassard, J.-É., Andersen-Ranberg, J., Møldrup, M. E., Simonsen, H. T., and Hamberger, B. (2014a). "High throughput testing of terpenoid biosynthesis candidate genes using transient expression in Nicotiana benthamiana," in Plant Isoprenoids, ed M. Rodríguez-Concepción (New York, NY: Springer), 245-255.

Bach, S. S., King, B. C., Zhan, X., Simonsen, H. T., and Hamberger, B. (2014b). "Heterologous stable expression of terpenoid biosynthetic genes using the moss Physcomitrella patens," in Plant Isoprenoids, ed M. Rodríguez-Concepción (New York, NY: Springer), 257-271.

Beale, M. H., Birkett, M. A., Bruce, T. J. A., Chamberlain, K., Field, L. M., Huttly, A. K., et al. (2006). Aphid alarm pheromone produced by transgenic plants affects aphid and parasitoid behavior. Proc. Natl. Acad. Sci. U.S.A. 103, 10509-10513. doi: $10.1073 /$ pnas.0603998103

Berger, R. G. (2007). Flavours and Fragrances Chemistry, Bioprocessing and Sustainability. Heidelberg: Springer. doi: 10.1007/978-3-540-49339-6 have greatly expanded the capacity for targeted genome editing in higher plants. The tools provided by zinc finger nucleases, TALENs, and the CRISPR/Cas9 reagents greatly facilitate generation of targeted deletions and insertions of foreign DNA. The moss Physcomitrella has been a popular model plant for targeted genome editing for nearly 20 years due to its native ability for efficient homologous recombination, and even with the advances being made with genome editing in higher plants, moss remains well-positioned to be a model for studying terpenoid biosynthesis as well. The molecular tools for algae and cyanobacteria are also growing, and these organisms may prove to be good hosts for terpenoid engineering. Thus, the benefits of using plant cells as chemical factories for complex plant derived compounds remains an attractive alternative to microbial systems as the technological gap between the platforms becomes smaller. Overall, in many cases, the benefits of plants as a production system can outweigh the slower generation time and other challenges, and resources for engineering terpenoid metabolism directly in planta should continue to be developed. The increased awareness and acceptance of plants as small molecule production hosts combined with the generation of tools and knowledge that can be used in future plant engineering projects will lead to further success, bringing us closer to more examples of industrial scale green cell factories for terpenoids and other valuable specialized metabolites.

Besumbes, Ó., Sauret-Gueto, S., Phillips, M. A., Imperial, S., RodriguezConcepcion, M., and Boronat, A. (2004). Metabolic engineering of isoprenoid biosynthesis in Arabidopsis for the production of taxadiene, the first committed precursor of taxol. Biotechnol. Bioeng. 88, 168-175. doi: 10.1002/bit.20237

Beyer, P. (2010). Golden rice and 'Golden' crops for human nutrition. N. Biotechnol. 27, 478-481. doi: 10.1016/j.nbt.2010.05.010

Blount, B. A., Weenink, T., Vasylechko, S., and Ellis, T. (2012). Rational diversification of a promoter providing fine-tuned expression and orthogonal regulation for synthetic biology. PLoS ONE 7:e33279. doi: 10.1371/journal.pone.0033279

Bruckner, K., and Tissier, A. (2013). High-level diterpene production by transient expression in Nicotiana benthamiana. Plant Methods 9:46. doi: 10.1186/17464811-9-46

Busch, M., Seuter, A., and Hain, R. (2002). Functional analysis of the early steps of carotenoid biosynthesis in tobacco. Plant Physiol. 128, 439-453. doi: 10.1104/pp.010573

Buttner-Mainik, A., Parsons, J., Jerome, H., Hartmann, A., Lamer, S., Schaaf, A., et al. (2011). Production of biologically active recombinant human factor $\mathrm{H}$ in Physcomitrella. Plant Biotechnol. J. 9, 373-383. doi: 10.1111/j.14677652.2010.00552.x

Carretero-Paulet, L., Cairo, A., Botella-Pavia, P., Besumbes, O., Campos, N. Boronat, A., et al. (2006). Enhanced flux through the methylerythritol 4-phosphate pathway in Arabidopsis plants overexpressing deoxyxylulose 5-phosphate reductoisomerase. Plant Mol. Biol. 62, 683-695. doi: 10.1007/s11103-006-9051-9

Chappell, J. (1995). Biochemistry and molecular-biology of the isoprenoid biosynthetic-pathway in plants. Annu. Rev. Plant Phys. 46, 521-547. doi: 10.1146/annurev.pp.46.060195.002513

Chappell, J., Wolf, F., Proulx, J., Cuellar, R., and Saunders, C. (1995). Is the reaction catalyzed by 3-hydroxy-3-methylglutaryl coenzyme-a reductase a rate-limiting step for isoprenoid biosynthesis in plants. Plant Physiol. 109, 1337-1343.

Choi, D., Bostock, R. M., Avdiushko, S., and Hildebrand, D. F. (1994). Lipidderived signals that discriminate wound-responsive and pathogen-responsive isoprenoid pathways in plants - methyl jasmonate and the fungal elicitor arachidonic-acid induce different 3-hydroxy-3-methylglutaryl-coenzyme-a 
reductase genes and antimicrobial isoprenoids in Solanum tuberosum L. Proc. Natl. Acad. Sci. U.S.A. 91, 2329-2333. doi: 10.1073/pnas.91.6.2329

Cordoba, E., Salmi, M., and Leon, P. (2009). Unravelling the regulatory mechanisms that modulate the MEP pathway in higher plants. J. Exp. Bot. 60, 2933-2943. doi: 10.1093/jxb/erp190

Cragg, G. M., Kingston, D. G. I., and Newman, D. J. (2011). Anticancer Agents from Natural Products. Boca Raton, FL: CRC Press. doi: 10.1201/b11185

Davidovich-Rikanati, R., Sitrit, Y., Tadmor, Y., Iijima, Y., Bilenko, N., Bar, E., et al. (2007). Enrichment of tomato flavor by diversion of the early plastidial terpenoid pathway. Nat. Biotechnol. 25, 899-901. doi: 10.1038/nbt1312

Daviet, J., and Schalk, M. (2010). Biotechnology in plant essential oil production: progress and perspective in metabolic engineering of the terpene pathway. Flavour Frag. J. 25, 123-127. doi: 10.1002/ffj.1981

Diaz-Chavez, M. L., Moniodis, J., Madilao, L. L., Jancsik, S., Keeling, C. I., Barbour, E. L., et al. (2013). Biosynthesis of sandalwood oil: Santalum album CYP76F cytochromes P450 produce santalols and bergamotol. PLoS ONE 8:e75053. doi: 10.1371/journal.pone.0075053

Drew, D. P., Dueholm, B., Weitzel, C., Zhang, Y., Sensen, C., and Simonsen, H. T. (2013). Transcriptome analysis of Thapsia laciniata Rouy provides insights into terpenoid biosynthesis and diversity in Apiaceae. Int. J. Mol. Sci. 14, 9080-9098. doi: 10.3390/ijms14059080

Drew, D. P., Krichau, N., Reichwald, K., and Simonsen, H. T. (2009). Guaianolides in Apiaceae: perspectives on pharmacology and biosynthesis. Phytochem. Rev. 8, 581-599. doi: 10.1007/s11101-009-9130-Z

Enfissi, E. M., Fraser, P. D., Lois, L. M., Boronat, A., Schuch, W., and Bramley, P. M. (2005). Metabolic engineering of the mevalonate and non-mevalonate isopentenyl diphosphate-forming pathways for the production of health-promoting isoprenoids in tomato. Plant Biotechnol. J. 3, 17-27. doi: 10.1111/j.14677652.2004.00091.x

Engels, B., Dahm, P., and Jennewein, S. (2008). Metabolic engineering of taxadiene biosynthesis in yeast as a first step towards Taxol (Paclitaxel) production. Metab. Eng. 10, 201-206. doi: 10.1016/j.ymben.2008.03.001

Estevez, J. M., Cantero, A., Reindl, A., Reichler, S., and Leon, P. (2001). 1-deoxy-D-xylulose-5-phosphate synthase, a limiting enzyme for plastidic isoprenoid biosynthesis in plants. J. Biol. Chem. 276, 22901-22909. doi: 10.1074/jbc.M100854200

Faye, L. C., and Gomord, V. R. (2009). Recombinant Proteins from Plants: Methods and Protocols. New York; London: Humana; Springer. doi: 10.1007/978-159745-407-0

Fray, R. G., Wallace, A., Fraser, P. D., Valero, D., Hedden, P., Bramley, P. M., et al. (1995). Constitutive expression of a fruit phytoene synthase gene in transgenic tomatoes causes dwarfism by redirecting metabolites from the gibberellin pathway. Plant J. 8, 693-701. doi: 10.1046/j.1365-313X.1995.08050693.x

Góngora-Castillo, E., Childs, K. L., Fedewa, G., Hamilton, J. P., Liscombe, D. K., Magallanes-Lundback, M., et al. (2012). Development of transcriptomic resources for interrogating the biosynthesis of monoterpene indole alkaloids in medicinal plant species. PLOS ONE 7:e52506. doi: 10.1371/journal.pone.0052506

Gong, Y. F., Liao, Z. H., Guo, B. H., Sun, X. F., and Tang, K. X. (2006). Molecular cloning and expression profile analysis of Ginkgo biloba DXS gene encoding 1-deoxy-D-xylulose 5-phosphate synthase, the first committed enzyme of the 2-C-methyl-D-erythritol 4-phosphate pathway. Planta Med. 72, 329-335. doi: $10.1055 / \mathrm{s}-2005-916234$

Hamberger, B., and Bak, S. (2013). Plant P450s as versatile drivers for evolution of species-specific chemical diversity. Philos. Trans. R. Soc. Lond. B Biol. Sci. 368, 1471-2970. doi: 10.1098/rstb.2012.0426

Han, J. L., Liu, B. Y., Ye, H. C., Wang, H., Li, Z. Q., and Li, G. F. (2006). Effects of overexpression of the endogenous farnesyl diphosphate synthase on the artemisinin content in Artemisia annua L. J. Integr. Plant Biol. 48, 482-487. doi: 10.1111/j.1744-7909.2006.00208.x

Han, M., Heppel, S. C., Su, T., Bogs, J., Zu, Y. G., An, Z. G., et al. (2013). Enzyme inhibitor studies reveal complex control of methyl-d-erythritol 4phosphate (MEP) pathway enzyme expression in Catharanthus roseus. PLoS ONE 8:e62467. doi: 10.1371/journal.pone.0062467

Kai, G., Xu, H., Zhou, C., Liao, P., Xiao, J., Luo, X., et al. (2011). Metabolic engineering tanshinone biosynthetic pathway in Salvia miltiorrhiza hairy root cultures. Metab. Eng. 13, 319-327. doi: 10.1016/j.ymben.2011. 02.003
Khemvong, S., and Suvachittanont, W. (2005). Molecular cloning and expression of a cDNA encoding 1-deoxy-d-xylulose-5-phosphate synthase from oil palm Elaeis guineensis Jacq. Plant Sci. 169, 571-578. doi: 10.1016/j.plantsci.2005.05.001

Kovacs, K., Zhang, L., Linforth, R. S., Whittaker, B., Hayes, C. J., and Fray, R. G. (2007). Redirection of carotenoid metabolism for the efficient production of taxadiene [taxa-4(5),11(12)-diene] in transgenic tomato fruit. Transgenic Res. 16, 121-126. doi: 10.1007/s11248-006-9039-x

Lange, B. M., and Ahkami, A. (2013). Metabolic engineering of plant monoterpenes, sesquiterpenes and diterpenes-current status and future opportunities. Plant Biotechnol. J. 11, 169-196. doi: 10.1111/pbi.12022

Lange, B. M., and Croteau, R. (1999). Genetic engineering of essential oil production in mint. Curr. Opin. Plant Biol. 2, 139-144. doi: 10.1016/S13695266(99)80028-4

Lavy, M., Zuker, A., Lewinsohn, E., Larkov, O., Ravid, U., Vainstein, A., et al. (2002). Linalool and linalool oxide production in transgenic carnation flowers expressing the Clarkia breweri linalool synthase gene. Mol. Breeding 9, 103-111. doi: $10.1023 / \mathrm{A}: 1026755414773$

Lee, S., and Chappell, J. (2008). Biochemical and genomic characterization of terpene synthases in Magnolia grandiflora. Plant Physiol. 147, 1017-1033. doi: $10.1104 / \mathrm{pp} .108 .115824$

Lewinsohn, E., Schalechet, F., Wilkinson, J., Matsui, K., Tadmor, Y., Nam, K. H., et al. (2001). Enhanced levels of the aroma and flavor compound $S$-linalool by metabolic engineering of the terpenoid pathway in tomato fruits. Plant Physiol. 127, 1256-1265. doi: 10.1104/pp.010293

Lohr, M., Schwender, J., and Polle, J. E. W. (2012). Isoprenoid biosynthesis in eukaryotic phototrophs: a spotlight on algae. Plant Sci. 185, 9-22. doi 10.1016/j.plantsci.2011.07.018

Lois, L. M., Rodriguez-Concepcion, M., Gallego, F., Campos, N., and Boronat, A. (2000). Carotenoid biosynthesis during tomato fruit development: regulatory role of 1-deoxy-D-xylulose 5-phosphate synthase. Plant J. 22, 503-513. doi: 10.1046/j.1365-313x.2000.00764.x

Lücker, J., Bouwmeester, H. J., Schwab, W., Blaas, J., Van Der Plas, L. H. W., and Verhoeven, H. A. (2001). Expression of Clarkia S-linalool synthase in transgenic petunia plants results in the accumulation of $S$-linalyl- $\beta-D$ glucopyranoside. Plant J. 27, 315-324. doi: 10.1046/j.1365-313x.2001.01097.x

Lücker, J., Schwab, W., Franssen, M. C., Van Der Plas, L. H. W., Bouwmeester, H. J., and Verhoeven, H. A. (2004a). Metabolic engineering of monoterpene biosynthesis: two-step production of (+)-trans-isopiperitenol by tobacco. Plant J. 39, 135-145. doi: 10.1111/j.1365-313X.2004.02113.x

Lücker, J., Schwab, W., van Hautum, B., Blaas, J., Van Der Plas, L. H. W., Bouwmeester, H. J., et al. (2004b). Increased and altered fragrance of tobacco plants after metabolic engineering using three monoterpene synthases from lemon. Plant Physiol. 134, 510-519. doi: 10.1104/pp.103.030189

Mahmoud, S. S., and Croteau, R. B. (2001). Metabolic engineering of essential oil yield and composition in mint by altering expression of deoxyxylulose phosphate reductoisomerase and menthofuran synthase. Proc. Natl. Acad. Sci. U.S.A. 98, 8915-8920. doi: 10.1073/pnas.141237298

Manavalan, L. P., Chen, X., Clarke, J., Salmeron, J., and Nguyen, H. T. (2012). RNAi-mediated disruption of squalene synthase improves drought tolerance and yield in rice. J. Exp. Bot. 63, 163-175. doi: 10.1093/jxb/err258

McGarvey, D. J., and Croteau, R. (1995). Terpenoid metabolism. Plant Cell 7, 1015-1026. doi: 10.1105/tpc.7.7.1015

Munoz-Bertomeu, J., Arrillaga, I., Ros, R., and Segura, J. (2006). Up-regulation of 1-deoxy-D-xylulose-5-phosphate synthase enhances production of essential oils in transgenic spike lavender. Plant Physiol. 142, 890-900. doi: $10.1104 / \mathrm{pp} .106 .086355$

Nielsen, M. T., Ranberg, J. A., Christensen, U., Christensen, H. B., Harrison, S. J., Olsen, C. E., et al. (2014). Microbial synthesis of the forskolin precursor manoyl oxide in enantiomerically pure form. Appl. Environ. Microbiol. 80, 7258-7265. doi: 10.1128/AEM.02301-14

Nieto, B., Fores, O., Arro, M., and Ferrer, A. (2009). Arabidopsis 3-hydroxy-3methylglutaryl-CoA reductase is regulated at the post-translational level in response to alterations of the sphingolipid and the sterol biosynthetic pathways. Phytochemistry 70, 53-59. doi: 10.1016/j.phytochem.2008.10.010

Ohara, K., Ujihara, T., Endo, T., Sato, F., and Yazaki, K. (2003). Limonene production in tobacco with Perilla limonene synthase cDNA. J. Exp. Bot. 54, 2635-2642. doi: 10.1093/jxb/erg300 
Ohto, C., Muramatsu, M., Obata, S., Sakuradani, E., and Shimizu, S. (2009). Overexpression of the gene encoding HMG-CoA reductase in Saccharomyces cerevisiae for production of prenyl alcohols. Appl. Microbiol. Biotechnol. 82, 837-845. doi: 10.1007/s00253-008-1807-5

Okada, A., Shimizu, T., Okada, K., Kuzuyama, T., Koga, J., Shibuya, N., et al. (2007). Elicitor induced activation of the methylerythritol phosphate pathway toward phytoalexins biosynthesis in rice. Plant Mol. Biol. 65, 177-187. doi: 10.1007/s11103-007-9207-2

Okada, K., Kasahara, H., Yamaguchi, S., Kawaide, H., Kamiya, Y., Nojiri, H., et al. (2008). Genetic evidence for the role of isopentenyl diphosphate isomerases in the mevalonate pathway and plant development in Arabidopsis. Plant Cell Physiol. 49, 604-616. doi: 10.1093/pcp/pcn032

Paddon, C. J., Westfall, P. J., Pitera, D. J., Benjamin, K., Fisher, K., McPhee, D., et al. (2013). High-level semi-synthetic production of the potent antimalarial artemisinin. Nature 496, 528-532. doi: 10.1038/nature12051

Page, J. E., Hause, G., Raschke, M., Gao, W. Y., Schmidt, J., Zenk, M. H., et al. (2004). Functional analysis of the final steps of the 1-Deoxy-D-xylulose 5phosphate (DXP) pathway to isoprenoids in plants using virus-induced gene silencing. Plant Physiol. 134, 1401-1413. doi: 10.1104/pp.103.038133

Pan, X.-W. (2014). Metabolic Engineering of the Diterpnoid Sclareol in the Moss Physcomitrella patens. $\mathrm{PhD}$ thesis, University of Copenhagen.

Pateraki, I., Andersen-Ranberg, J., Hamberger, B., Heskes, A. M., Martens, H. J., Zerbe, P., et al. (2014). Manoyl oxide (13R), the biosynthetic precursor of forskolin, is synthesized in specialized root cork cells in Coleus forskohlii. Plant Physiol. 164, 1222-1236. doi: 10.1104/pp.113.228429

Pateraki, I., Heskes, A., and Hamberger, B. (2015). Cytochromes P450 for Terpene Functionalisation and Metabolic Engineering. Berlin; Heidelberg: Springer.

Pickel, B., Drew, D. P., Manczak, T., Weitzel, C., Simonsen, H. T., and Ro, D. K. (2012). Identification and characterization of a kunzeaol synthase from Thapsia garganica: implications for the biosynthesis of the pharmaceutical thapsigargin. Biochem. J. 448, 261-271. doi: 10.1042/BJ20120654

Ro, D. K., Paradise, E. M., Ouellet, M., Fisher, K. J., Newman, K. L., Ndungu, J. M., et al. (2006). Production of the antimalarial drug precursor artemisinic acid in engineered yeast. Nature 440, 940-943. doi: 10.1038/nature04640

Robert, C. A., Erb, M., Hiltpold, I., Hibbard, B. E., Gaillard, M. D., Bilat, J., et al. (2013). Genetically engineered maize plants reveal distinct costs and benefits of constitutive volatile emissions in the field. Plant Biotechnol. J. 11, 628-639. doi: $10.1111 /$ pbi. 12053

Rodriguez-Concepcion, M., Botella-Pavia, P., Besumbes, O., Phillips, M. A., Carretero-Paulet, L., and Boronat, A. (2004). Regulation of carotenoid biosynthesis in plants: evidence for a key role of hydroxymethylbutenyl diphosphate reductase in controlling the supply of plastidial isoprenoid precursors. Plant J. 40, 188-199. doi: 10.1111/j.1365-313X.2004.02198.x

Rohmer, M., Knani, M., Simonin, P., Sutter, B., and Sahm, H. (1993). Isoprenoid biosynthesis in bacteria: a novel pathway for the early steps leading to isopentenyl diphosphate. Biochem. J. 295, 517-524.

Sallaud, C., Rontein, D., Onillon, S., Jabes, F., Duffe, P., Giacalone, C., et al. (2009). A novel pathway for sesquiterpene biosynthesis from Z,Z-farnesyl pyrophosphate in the wild tomato Solanum habrochaites. Plant Cell 21, 301-317. doi: 10.1105/tpc.107.057885

Sanmiya, K., Ueno, O., Matsuoka, M., and Yamamoto, N. (1999). Localization of farnesyl diphosphate synthase in chloroplasts. Plant Cell Physiol. 40, 348-354. doi: 10.1093/oxfordjournals.pcp.a029549

Shuiqin, W., Schalk, M., Clark, A., Miles, R. B., Coates, R., and Chappell, J. (2006). Redirection of cytosolic or plastidic isoprenoid precursors elevates terpene production in plants. Nat. Biotechnol. 24, 1441-1447. doi: 10.1038/nbt1251

Simonsen, H. T., Drew, D. P., and Lunde, C. (2009). Perspectives on using Physcomitrella patens as an alternative production platform for thapsigargin and other terpenoid drug candidates. Perspect. Med. Chem. 3, 1-6.

Sommer, S., Severin, K., Camara, B., and Heide, L. (1995). Intracellular localization of geranylpyrophosphate synthase from cell cultures of Lithospermum erythrorhizon. Phytochemistry 38, 623-627. doi: 10.1016/0031-9422(94) 00684-L

Song, A. A., Abdullah, J. O., Abdullah, M. P., Shafee, N., Othman, R., Tan, E. F., et al. (2012). Overexpressing 3-hydroxy-3-methylglutaryl coenzyme A reductase (HMGR) in the lactococcal mevalonate pathway for heterologous plant sesquiterpene production. PLoS ONE 7:e52444. doi: 10.1371/journal.pone. 0052444
Stermer, B. A., Bianchini, G. M., and Korth, K. L. (1994). Regulation of Hmg-Coa reductase-activity in plants. J. Lipid Res. 35, 1133-1140.

Takahashi, S., Yeo, Y., Greenhagen, B. T., McMullin, T., Song, L., MaurinaBrunker, J., et al. (2007). Metabolic engineering of sesquiterpene metabolism in yeast. Biotechnol. Bioeng. 97, 170-181. doi: 10.1002/bit.21216

Ting, H.-M., Wang, B., Rydén, A.-M., Woittiez, L., Van Herpen, T., Verstappen, F. W. A., et al. (2013). The metabolite chemotype of Nicotiana benthamiana transiently expressing artemisinin biosynthetic pathway genes is a function of CYP71AV1 type and relative gene dosage. New Phytol. 199, 352-366. doi: $10.1111 /$ nph.12274

Tsuruta, H., Paddon, C. J., Eng, D., Lenihan, J. R., Horning, T., Anthony, L. C., et al. (2009). High-level production of amorpha-4,11-diene, a precursor of the antimalarial agent artemisinin, in Escherichia coli. PLoS ONE 4:e4489. doi: 10.1371/journal.pone.0004489

Vaccaro, M., Malafronte, N., Alfieri, M., De Tommasi, N., and Leone, A. (2014). Enhanced biosynthesis of bioactive abietane diterpenes by overexpressing AtDXS or AtDXR genes in Salvia sclarea hairy roots. Plant Cell Tissue Organ Cult. 119, 65-77. doi: 10.1007/s11240-014-0514-4

Van Herpen, T. W., Cankar, K., Nogueira, M., Bosch, D., Bouwmeester, H. J., and Beekwilder, J. (2010). Nicotiana benthamiana as a production platform for artemisinin precursors. PLOS ONE 5:e14222. doi: 10.1371/journal.pone.0014222

Vasilev, N., Schmitz, C., Dong, L., Ritala, A., Imseng, N., Häkkinen, S., et al. (2014). Comparison of plant-based expression platforms for the heterologous production of geraniol. Plant Cell Tissue Organ Cult. 117, 373-380. doi: 10.1007/s11240-014-0446-z

Venter, M. (2007). Synthetic promoters: genetic control through cis engineering. Trends Plant Sci. 12, 118-124. doi: 10.1016/j.tplants.2007. 01.002

Von Schwartzenberg, K., Schultze, W., and Kassner, H. (2004). The moss Physcomitrella patens releases a tetracyclic diterpene. Plant Cell Rep. 22, 780-786. doi: 10.1007/s00299-004-0754-6

Wallaart, T. E., Bouwmeester, H. J., Hille, J., Poppinga, L., and Maijers, N. C. (2001). Amorpha-4,11-diene synthase: cloning and functional expression of a key enzyme in the biosynthetic pathway of the novel antimalarial drug artemisinin. Planta 212, 460-465. doi: 10.1007/s0042500 00428

Walter, M. H., Fester, T., and Strack, D. (2000). Arbuscular mycorrhizal fungi induce the non-mevalonate methylerythritol phosphate pathway of isoprenoid biosynthesis correlated with accumulation of the 'yellow pigment' and other apocarotenoids. Plant J. 21, 571-578. doi: 10.1046/j.1365-313x.2000.0 0708.x

Wang, H., Nagegowda, D. A., Rawat, R., Bouvier-Navé, P., Guo, D., Bach, T. J., et al. (2012). Overexpression of Brassica juncea wild-type and mutant HMGCoA synthase 1 in Arabidopsis up-regulates genes in sterol biosynthesis and enhances sterol production and stress tolerance. Plant Biotechnol. J. 10, 31-42. doi: 10.1111/j.1467-7652.2011.00631.x

Weissenborn, D. L., Denbow, C. J., Laine, M., Lang, S. S., Yang, Z., Yu, X., et al. (1995). HMG-GoA reductase and terpenoid phytoalexins: molecular specialization within a complex pathway. Physiol. Plant. 93, 393-400. doi: 10.1111/j.1399-3054.1995.tb02244.x

Weitzel, C., and Simonsen, H. (2013). Cytochrome P450-enzymes involved in the biosynthesis of mono- and sesquiterpenes. Phytochem. Rev. 1-18. doi: $10.1007 / \mathrm{s} 11101-013-9280-\mathrm{x}$

Wu, S., and Chappell, J. (2008). Metabolic engineering of natural products in plants; tools of the trade and challenges for the future. Curr. Opin. Biotechnol. 19, 145-152. doi: 10.1016/j.copbio.2008.02.007

Xiang, L., Zeng, L. X., Yuan, Y., Chen, M., Wang, F., Liu, X. Q., et al. (2012). Enhancement of artemisinin biosynthesis by overexpressing dxr, cyp7lav1 and cpr in the plants of Artemisia annua L. Plant Omics 5, 503-507.

Yang, K., Monafared, R., Wang, H., Lundgren, A., and Brodelius, P. (2015). The activity of the artemisinic aldehyde $\Delta 11(13)$ reductase promoter is important for artemisinin yield in different chemotypes of Artemisia annua L. Plant Mol. Biol. 1-16. doi: 10.1007/s11103-015-0284-3

Ye, X., Al-Babili, S., Klöti, A., Zhang, J., Lucca, P., Beyer, P., et al. (2000). Engineering the provitamin $A$ ( $\beta$-Carotene) biosynthetic pathway into (carotenoid-free) rice endosperm. Science 287, 303-305. doi: 10.1126/science.287.5451.303 
Zhan, X., Han, L. A., Zhang, Y., Chen, D., and Simonsen, H. T. (2014). Metabolic engineering of the moss Physcomitrella patens to produce the sesquiterpenoids patchoulol and $\alpha / \beta-$ santalene. Front. Plant Sci. 5:636. doi: 10.3389/fpls.2014.00636

Zhang, Y., Nowak, G., Reed, D. W., and Covello, P. S. (2011). The production of artemisinin precursors in tobacco. Plant Biotechnol. J. 9, 445-454. doi: 10.1111/j.1467-7652.2010. 00556.x

Zwenger, S., and Basu, C. (2008). Plant terpenoids: applications and future potentials. Biotechnol. Mol. Biol. Rev. 3, 1-7.
Conflict of Interest Statement: The authors declare that the research was conducted in the absence of any commercial or financial relationships that could be construed as a potential conflict of interest.

Copyright $\odot 2015$ Ikram, Zhan, Pan, King and Simonsen. This is an open-access article distributed under the terms of the Creative Commons Attribution License (CC $B Y)$. The use, distribution or reproduction in other forums is permitted, provided the original author(s) or licensor are credited and that the original publication in this journal is cited, in accordance with accepted academic practice. No use, distribution or reproduction is permitted which does not comply with these terms. 